\title{
Housing for Now and the Future: A Systematic Review of Climate-Adaptive Measures
}

\author{
Ma Katrina Rañeses ${ }^{1, *(\mathbb{D},}$, Alice Chang-Richards ${ }^{1}$, Kevin I-Kai Wang ${ }^{2}{ }^{(\mathbb{C}}$ and Kim Natasha Dirks ${ }^{1}$ (D) \\ 1 Department of Civil and Environmental Engineering, Faculty of Engineering, The University of Auckland, \\ Auckland 1010, New Zealand; yan.chang@auckland.ac.nz (A.C.-R.); k.dirks@auckland.ac.nz (K.N.D.) \\ 2 Department of Electrical, Computer and Software Engineering, Faculty of Engineering, The University \\ of Auckland, Auckland 1010, New Zealand; kevin.wang@auckland.ac.nz \\ * Correspondence: mrae569@aucklanduni.ac.nz; Tel.: +64-27-4211019
}

Citation: Rañeses, M.K.;

Chang-Richards, A.; Wang, K.I-K.;

Dirks, K.N. Housing for Now and the Future: A Systematic Review of

Climate-Adaptive Measures.

Sustainability 2021, 13, 6744 .

https://doi.org/10.3390/su13126744

Academic Editor: Giouli Mihalakakou

Received: 19 May 2021

Accepted: 9 June 2021

Published: 15 June 2021

Publisher's Note: MDPI stays neutral with regard to jurisdictional claims in published maps and institutional affiliations.

Copyright: (c) 2021 by the authors. Licensee MDPI, Basel, Switzerland. This article is an open access article distributed under the terms and conditions of the Creative Commons Attribution (CC BY) license (https:// creativecommons.org/licenses/by/ $4.0 /)$.

\begin{abstract}
Climate change requires our built environment to be adaptable in order to serve the community well. Among the components of the built environment, housing and its occupants are especially vulnerable. Over the years, there have been variations in the designs and building techniques used in the construction of houses able to adapt to these changes. In this study, a systematic review with the preferred reporting items for systematic review and meta-analyses (PRISMA) protocol was conducted to identify, classify, and investigate existing climate-adaptive measures for housing on the basis of 65 articles selected. In total, 21 climate-adaptive measures were identified and classified into three categories, namely, passive design, building technology, and building performance assessment tools. From the identified climate-adaptive measures, 16 distinct benefits were identified, the majority of which are related to improved thermal comfort and energy efficiency. This review lays the foundation for further research examining the roles of existing, new, and emerging technologies in enhancing building performance and the adaptive ability of houses in response to climate change.
\end{abstract}

Keywords: built environment; climate change; housing; climate adaptation; systematic review

\section{Introduction}

Housing is widely regarded as one of the primary and most critical human needs and human rights [1]. It is also fundamental in forming a community, and plays a vital role in community coherence [2]. The housing standards established by the United Nations (UN) include categories such as security of tenure; the availability of services, materials, facilities, and infrastructure; affordability; habitability; accessibility; location and cultural adequacy. To meet all of these requirements, the design and plan of a house need to consider all potential changes in the environment that would affect housing performance [3].

Among all these changes in the environment, climate change has become one of the greatest humanitarian challenges facing society [4]. Climate change is known to many people in the form of changing weather patterns, sea levels rising, and increasing global temperatures [5]. Over the past decade, it has reached the top of the political agenda in many countries. The impact of climate change is diverse, ranging from flash flooding, caused by torrential rains, to coastal erosion and heatwaves. The root cause of climate change, however, is believed to be the anthropogenic actions of humans, such as the burning of fossil fuels, deforestation, land-use changes, the decomposition of waste in landfills, soil cultivation practices, and chlorofluorocarbon applications [6]. According to the Intergovernmental Panel on Climate Change [6], the global average temperature is increasing at a rate of between $0.8^{\circ} \mathrm{C}$ and $1.2^{\circ} \mathrm{C}$ per decade, and will likely reach a rate of $1.5^{\circ} \mathrm{C}$ per decade between 2030 and 2052. However, the impact of such temperature increases on our natural systems and human societies is uncertain, as the rate, peak and 
duration of warming depend at least in part on the mitigation and adaption measures that are implemented.

Research into climate change and housing has shown that among built structures, housing and its occupants are especially vulnerable to climate change [7]. For example, high temperatures can cause overheating in a house that does not have any proper cooling appliances or measures [8]. In some cases, extreme heat experienced inside the house can lead to health problems and even death in its inhabitants [9]. As the occurrence of extreme weather becomes more common, the durability and structural integrity of a house may become compromised [10]. Statistics from the emergency events database (EM-DAT) show that, over the past 10 years, the estimated value of all damage and economic losses due to weather-related events is considerable. In 2019, worldwide, this totaled approximately USD 150 billion [11]. In New Zealand, specifically, climate-related events lead to around NZD 17.8 million (USD 12.6 million) in damage per year [11]. Similarly, the cost is estimated at over USD 54 billion per year for the United States of America, over USD 22 billion per year for China, and nearly USD 7 billion per year for Japan [11]. These costs account for approximately $0.01 \%, 0.25 \%, 0.08 \%$, and $0.14 \%$ of the national GDP for New Zealand, the USA, China, and Japan, respectively.

In addition, the construction of housing also contributes to climate change. A report from the UN Environment and International Energy Agency [12] suggested that, on average, buildings contribute $30 \%$ to total energy consumption, of which $22 \%$ comes from the housing sector. In addition, buildings account for $28 \%$ of global energy-related carbon dioxide emissions, of which $17 \%$ are related to residential houses [12]. Given the role that housing plays in driving climate change, it has been suggested that housing could be a mediator between climate change and human society [13].

Over the past decade, two concepts, namely, adaptation and mitigation, have become the main paradigms governing the response of the built environment to a changing climate [14]. While mitigation involves efforts to minimize or prevent greenhouse gas (GHG) emissions through the design of more energy-efficient buildings [15], adaptation refers to the adjustments needed to cope with the effects of climate change [16]. Mitigation solutions include sustainable housing [17], low-carbon or low-energy housing [18], and net-zero energy or net-zero carbon buildings [4]. Adaptive strategies, however, often include passive building designs to improve heating, ventilation, and air conditioning (HVAC) [19], the incorporation of resilience concepts into building design [20], and the use of smart technologies to improve thermal comfort [21-24]. It has to be noted that some climate adaptation measures, such as passive building design to improve the HVAC of a building, are often used together with mitigation strategies when reducing a building's carbon footprint through reduced energy consumption [25].

\section{Background}

Comparisons between buildings and the natural world have been carried out long before climate change reached the top of the agenda. Humans have always been in need of shelter to protect themselves against unfavorable environmental conditions [26]. While buildings provide this protection, they may also act as a threat to the natural environment in terms of resource consumption and depletion [27]. Unfortunately, the paradox is that, in the context of climate change, the built environment both affects it and is affected by it.

Designing shelters and structures to conform to specific climatic conditions is not a new concept. As early as in the fourth century BC, architects and builders were already considering the importance of designing buildings to conform to a particular climate. For instance, the windows of a house were often oriented towards the sun's path to capture heat and light, whereas walls with exterior stucco rendering were built to block sunlight and keep an area cool [28]. Over the past several thousand years, building techniques have been developed with a view to making houses more resilient to extreme environmental conditions. It was not until the past three decades that climate change's effects on the built 
environment have warranted a shift in the building design paradigm from traditional to contemporary, with climate mitigation and adaptation [29].

According to Kinnane et al. [3], both climate mitigation and adaptation embody new technologies and/or processes to achieve buildings that are resilient to the changes in the environment. Thus, continuous efforts in research and development are underway to address these changes and improve the functionality of the built environment. For instance, the Intergovernmental Panel on Climate Change (IPCC) has started gathering and presenting scientific evidence about climate change and the challenges that it poses. This has involved international collaboration from the 1990s up to the present day, with outcomes presented through regular releases of the IPCC assessment reports, comprehensive scientific reports aimed at addressing the current climate situation for adaptation and mitigation, and integration into sustainable development policies. Other global initiatives include the formation of the United Nations Framework Convention on Climate Change (UNFCCC) in 1994; the Berlin Mandate in 1995 which laid the basis for the Kyoto Protocol; the adoption of the Kyoto Protocol in 1997, the first GHG emissions reduction treaty; the launch of the European Union (EU) Emissions Trading Scheme in 2005, one of the major pillars of the EU climate policy; and the adoption of the Bali Road Map in 2007 which identified new processes for addressing climate change, through the Bali Action Plan and its five main categories: shared vision, mitigation, adaptation, technology, and financing.

Compared with mitigation, adaption deals with the development of ways to protect both people and the built environment by reducing their vulnerability to climate impacts. Most of the time, it is studied at the sectoral level, and can be seen as direct damage prevention [30]. Adaptation also enhances resilience and introduces an adaptive capacity regarding changes in climate. Moreover, adaptation occurs in multiple ways, some of which are related to technologies or innovations, while others are fueled by government policies and society in general [14].

Although climate adaption principles have been recognized as essential in making houses more climate-resilient, there is no holistic understanding of the types of measures available and their associated benefits and challenges with respect to implementation. A better understanding of existing climate-adaptive measures for buildings, especially for the housing sector, would help us enhance the theory on how the built environment can mediate to reduce the effects of climate change. Furthermore, climate adaptation measures are often examined independently, but they are often used in combination to achieve certain building functions. It is therefore important to understand how different measures can be taken together by considering housing as a system. This understanding will pave the way for exploring the mechanisms whereby humans, the physical built environment, and the natural environment interplay in driving or reversing climate change trends.

In this systematic review, we aim to address the following research questions:

1. What measures have been used to make houses adaptable to rising global temperatures in light of climate change?

2. What are the benefits of applying these measures in a housing system?

The methodology used in the systematic review is presented in the next section. The results, aligned with the two research questions, are then used to propose a framework for climate-adaptive housing which incorporates and categorizes the measures identified in the systematic review. Suggestions for how researchers and practitioners may make use of the findings, along with future research directions, are provided.

\section{Materials and Methods}

A systematic review approach was used to investigate the climate-adaptive measures that have been used in buildings, with a focus on the housing sector. The approach has been used primarily in the field of medicine [31], and is now commonly used in other disciplines such as management science [32], construction management [33], the built environment [27,34], management systems [35], and computer science [36]. Compared with a conventional literature review, a systematic review uses a systematic and documented 
process for identifying, selecting, screening, and synthesizing the literature for inclusion in the review [31]. It uses a methodical scheme that includes a comprehensive set of standards or pre-defined eligibility criteria to rate the reliability and validity of the literature [37-39]. According to Shamseer et al. [39], because of its exactness, transparency, reproducibility, and completeness, the systematic review method is considered valuable in providing a reliable evaluation of studies from which researchers can form conclusions, make decisions, and identify gaps in their topic of interest. However, one of the potential limitations of applying this method lies in the selection process. The set of article selection criteria determined for the literature search may be subject to the opinion of the person (s) evaluating the criteria; therefore, some relevant articles that do not meet the selection criteria may be excluded [36].

As shown in Figure 1, a protocol for this review was developed based on the preferred reporting items for systematic review and meta-analyses (PRISMA) protocol guidelines [37,39]. This process consists of four distinct stages, namely: (1) the identification of articles; (2) the screening of articles; (3) an eligibility assessment of articles; and (4) inclusion and synthesis. The identification of articles began in July 2019 and was completed in December 2019.

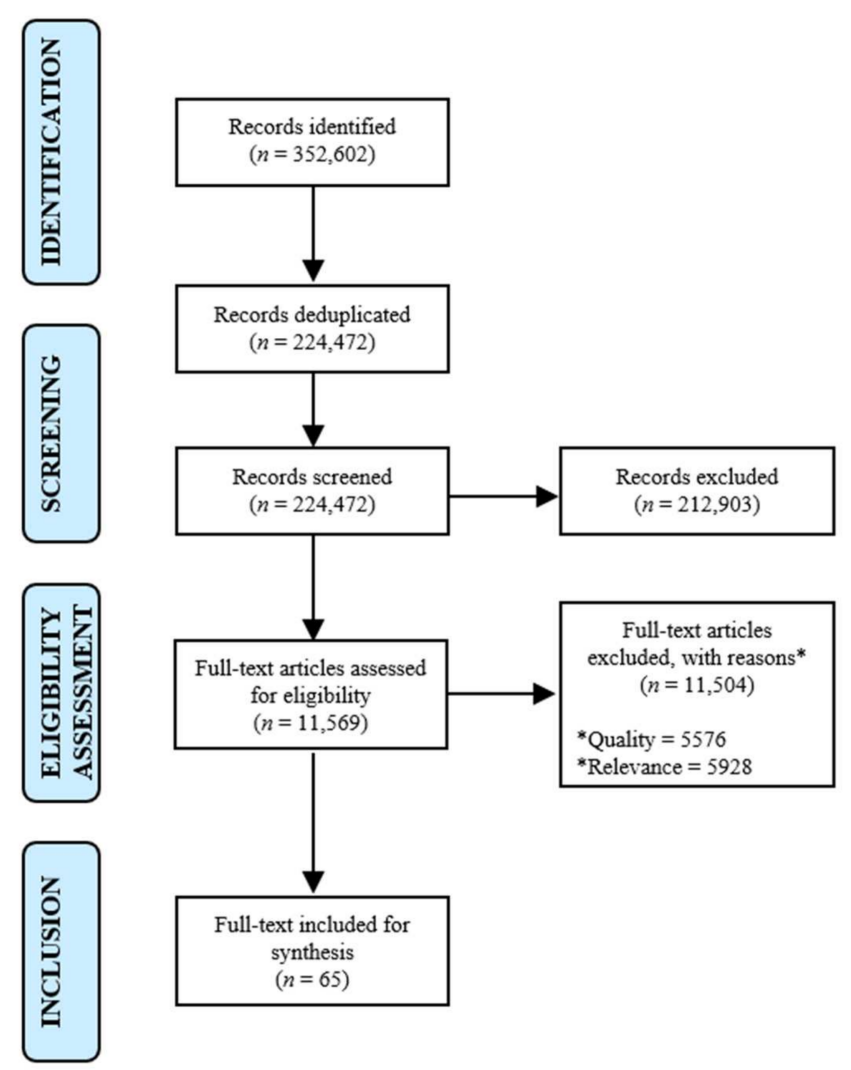

Figure 1. Flowchart of the review process (PRISMA flow diagram).

\section{Step 1: Identification of Articles}

Three databases, namely, Scopus, Engineering Village, and Science Direct, were selected for searching relevant articles. These databases were chosen as they each contain a wide range of research articles that cover the sciences, engineering, medicine, social sciences, and the arts [40]. The search was limited to ("environment" ${ }^{* \prime}$ OR "climate") AND ("hous*" OR "building*") as the terms. In the initial search, only literature published from January 1990 to December 2019 was included. The year 1990 was chosen because it aligned with the United Nations framework convention on climate change (UNFCCC), the first initiative that drew attention worldwide to the effects of climate change. The search also 
only included full-text research articles and those written in English. On the basis of these criteria, the initial search generated a total of 352,602 articles.

\section{Step 2: Screening of Articles}

With these 352,602 records, at this screening step, the duplicates were removed, and an initial check was carried out with respect to the relevance of an article, by cross-checking all of the records across the three databases. In addition, a total of 128,130 duplicates were removed, resulting in 224,472 articles for screening. Next in the screening process, both the title and abstract of each article were checked, and on this basis, a decision was made about whether or not an article was in the scope and thus should be included in the review. This resulted in the removal of 212,903 articles, leaving 11,569 for further eligibility assessment.

\section{Step 3: Eligibility Assessment of Articles}

In this step, an eligibility assessment was carried out for the remaining 11,569 articles based on three criteria: (1) the quality of the article, (2) the relevance to the research questions, and (3) the rigor of the methodology. The quality assessment was based on the metrics of the journal in which the article was published. Among journal metrics, such as the Journal Impact Factor (JIF), the SCImago Journal and Country Rank (SJR), and the Source Normalized Impact per Paper (SNIP) [41], SJR was selected as it also assesses a journal's rank using quartiles in a specific research area [42]. In our review, to ensure we only included high-quality articles, only those published in Quartile 1 (Q1) and Quartile 2 (Q2) journals were included, representing the top 25\% and 25-50\% of journals, respectively. This resulted in a total of 5993 articles retained.

A detailed relevance check was then conducted with those 5,993 articles to assess to what degree an article contained relevant information for answering the research questions as set out. A rating scale of relevance was used, consisting of "low", "medium", and "high", with an assigned grade of "1", " 2 ", and " 3 ", respectively. An article was rated as " 1 " indicating "low" relevance if it only mentioned or described certain climate-adaptive measures, without providing a detailed discussion about the challenges or benefits of using them. A rating of " 2 " was assigned if the article described the application of a certain adaptive measure but did not provide any substantial data or empirical studies to demonstrate the associated benefits. A rating of " 3 ", high relevance, was assigned to articles that described certain climate-adaptive measures in detail, and discussed the benefits of their implementation, with detailed experiments or case studies. For the purpose of this review, only those articles of high relevance (rated " 3 ") and thus published in highquality peer-reviewed journals (Q1 and Q2) were included. This relevance check resulted in 65 articles.

\section{Step 4: Inclusion and Synthesis of Selected Articles}

With the remaining 65 articles, a content analysis [43] was undertaken to identify the key themes and extract critical information from each article. The information, including the title of the article, the names of the authors, the publication year, the source of the publication, the country of the affiliation of the first author, the country under investigation (the studied region), the climate zone of the studied region, the climate-adaptive measures discussed, and the benefits and the challenges associated with using these climate-adaptive measures, were extracted from each article and imported into an Excel spreadsheet. Further descriptive statistical analyses were then undertaken to answer the research questions. A synthesis of the results is presented in the next section.

\section{Results}

\subsection{Summary of the Selected Articles}

4.1.1. Distribution of Papers within the Period of 1990 to 2019

Figure 2 presents the temporal distribution of papers included in this review. Although the United Nations Framework Convention on Climate Change (UNFCCC) was first initiated in 1990 as a call for action to combat climate change, there was a vacuum of relevant research published between 1990 and 2000, and there were only seven articles 
published in the subsequent decade, from 2001 to 2010. It was only after the year 2011 that a significant increase in research-related climate-adaptive measures for buildings developed, as reflected in the sudden growth of material that appeared in 2015 (9 articles) and 2019 (16 articles).

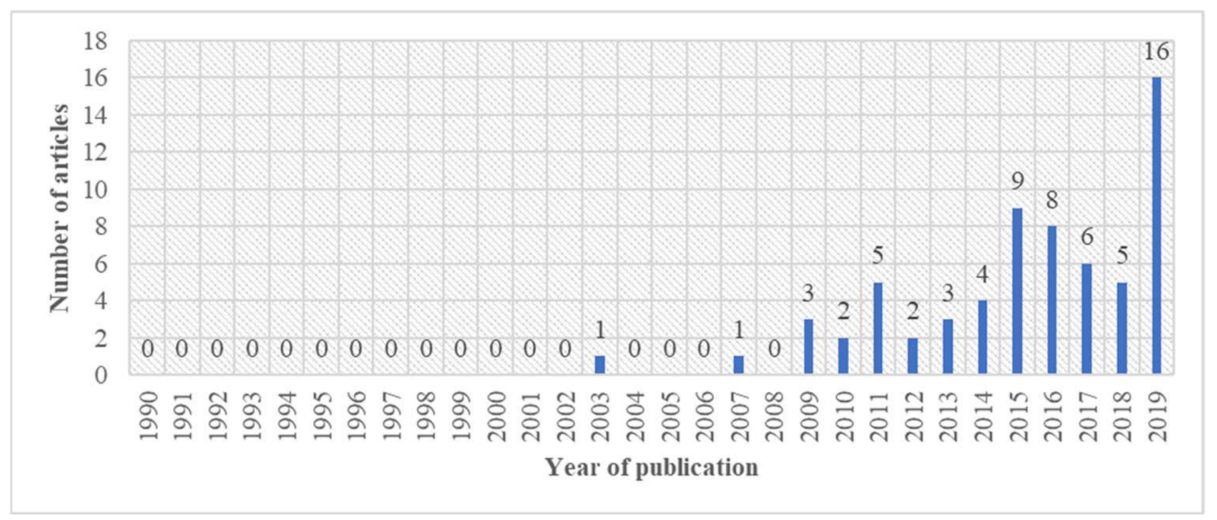

Figure 2. Distribution of journal articles published within the review period.

\subsubsection{Distribution of Papers Based on Publication Source}

Based on the SJR metric, $82 \%$ of the articles included were published in what are considered to be Q1 journals, and 18\% in Q2 journals. Table 1 shows the distribution of articles based on the publication source. The three most commonly selected journals for the papers identified in this review were "Energy and Buildings" (with 14 articles out of 65, 21.54\%), followed by "Building and Environment" ( 6 articles out of $65,9.23 \%$ ) and finally, "Buildings" ( 5 articles out of $65,7.69 \%$ ). Overall, the majority of the selected papers (46 articles out of $65,70.77 \%$ ) were published in 12 journals, while the remaining articles (19 articles out of $65,29.23 \%$ ) were published in 19 different journals, and grouped as "Other journals" in Table 1.

Table 1. Summary of the distribution of papers based on publication source.

\begin{tabular}{ccc}
\hline Publication Source & Count & Percentage (\%) \\
\hline Energy and Buildings & 14 & 21.54 \\
Building and Environment & 6 & 9.23 \\
Buildings & 5 & 7.69 \\
Journal of Engineering Sustainability & 3 & 4.62 \\
Sustainability (Switzerland) & 3 & 4.62 \\
Sustainable Cities and Society & 3 & 4.62 \\
Alexandria Engineering Journal & 2 & 3.08 \\
Building Simulation & 2 & 3.08 \\
Energies & 2 & 3.08 \\
Energy & 2 & 3.08 \\
International Journal of Ventilation & 2 & 3.08 \\
Journal of Building Engineering & 2 & 3.08 \\
Other journals & 19 & 29.23 \\
\hline Total & 65 & 100.00 \\
\hline
\end{tabular}

\subsubsection{Distribution of Papers Based on the Country of Affiliation of the Lead Author}

Figure 3 shows the geographical distribution of the papers, based on the first author's country of affiliation. By aggregating the countries into continents, we found that the 65 articles came from researchers from 34 countries, across four continents. Researchers in the UK are the most frequent lead authors, accounting for $14 \%$ of the selected articles ( 9 articles out of 65), followed by Australia and China contributing $8 \%$ ( 5 articles) each. In filtering by region, the European region shows strong involvement in this research 
topic, contributing $42 \%$ of the selected articles ( 27 articles) as lead author, followed by Asia accounting for $34 \%$ (22 articles), and Oceania and America each contributing 12\% (8 each) of the selected articles.

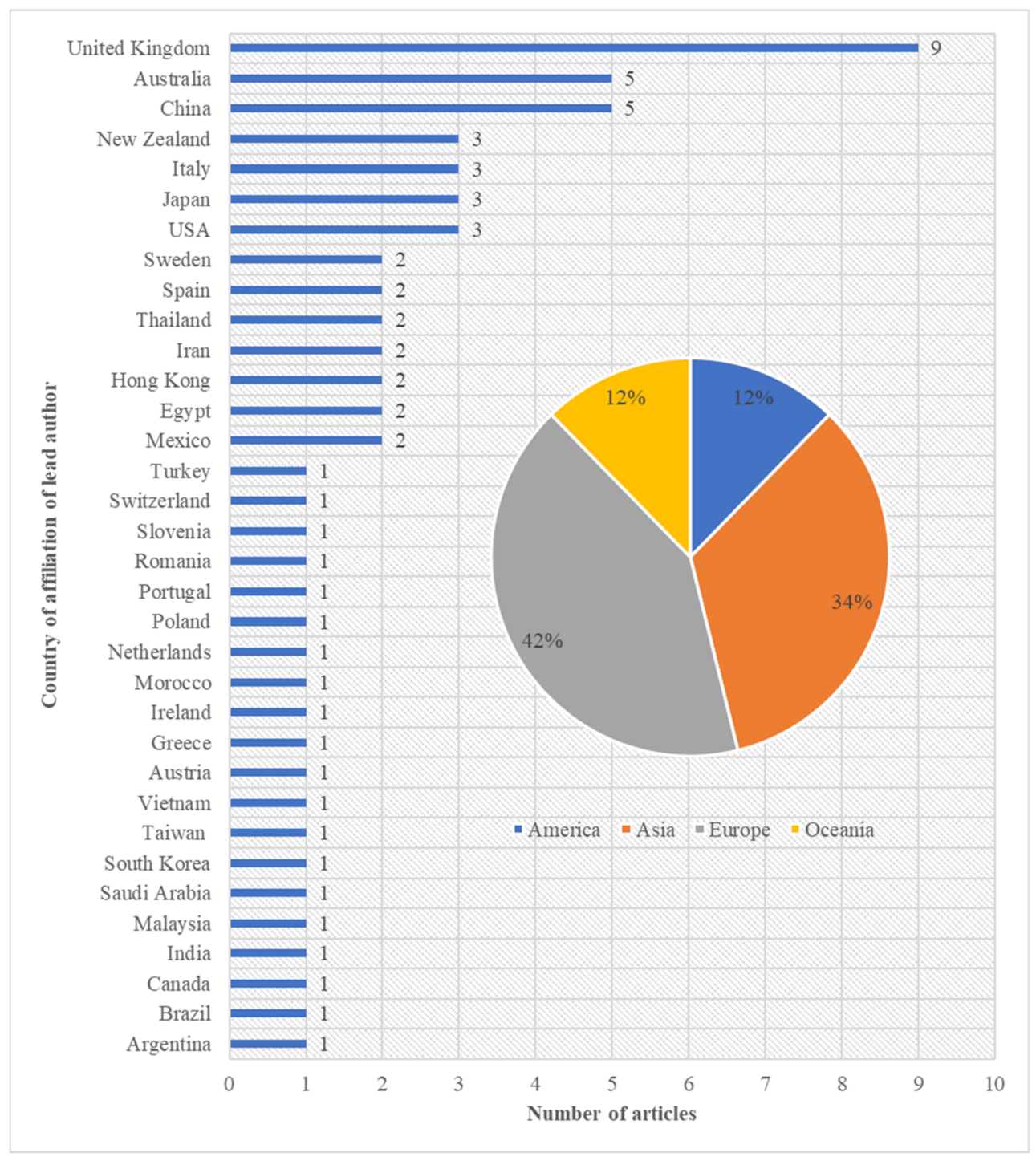

Figure 3. Distribution of papers based on the lead author's country of affiliation.

\subsubsection{Distribution of Papers Based on the Country under Investigation}

According to the country that was studied in the selected articles (Figure 4), a total of 42 countries across five continents have been studied (Figure 4). Seven articles reported research that was carried out in China (9\%). Both Australia and the UK were targeted as study areas in six of the articles (8\%). Overall, there are 33 articles $(45 \%)$ that reported research undertaken in Europe, followed by Asia with 20 articles $(27 \%)$ and Oceania with 9 articles $(12 \%)$. Note that the total number of countries under review is different from the total number of articles, as multiple locations were under study across several of the selected articles. 


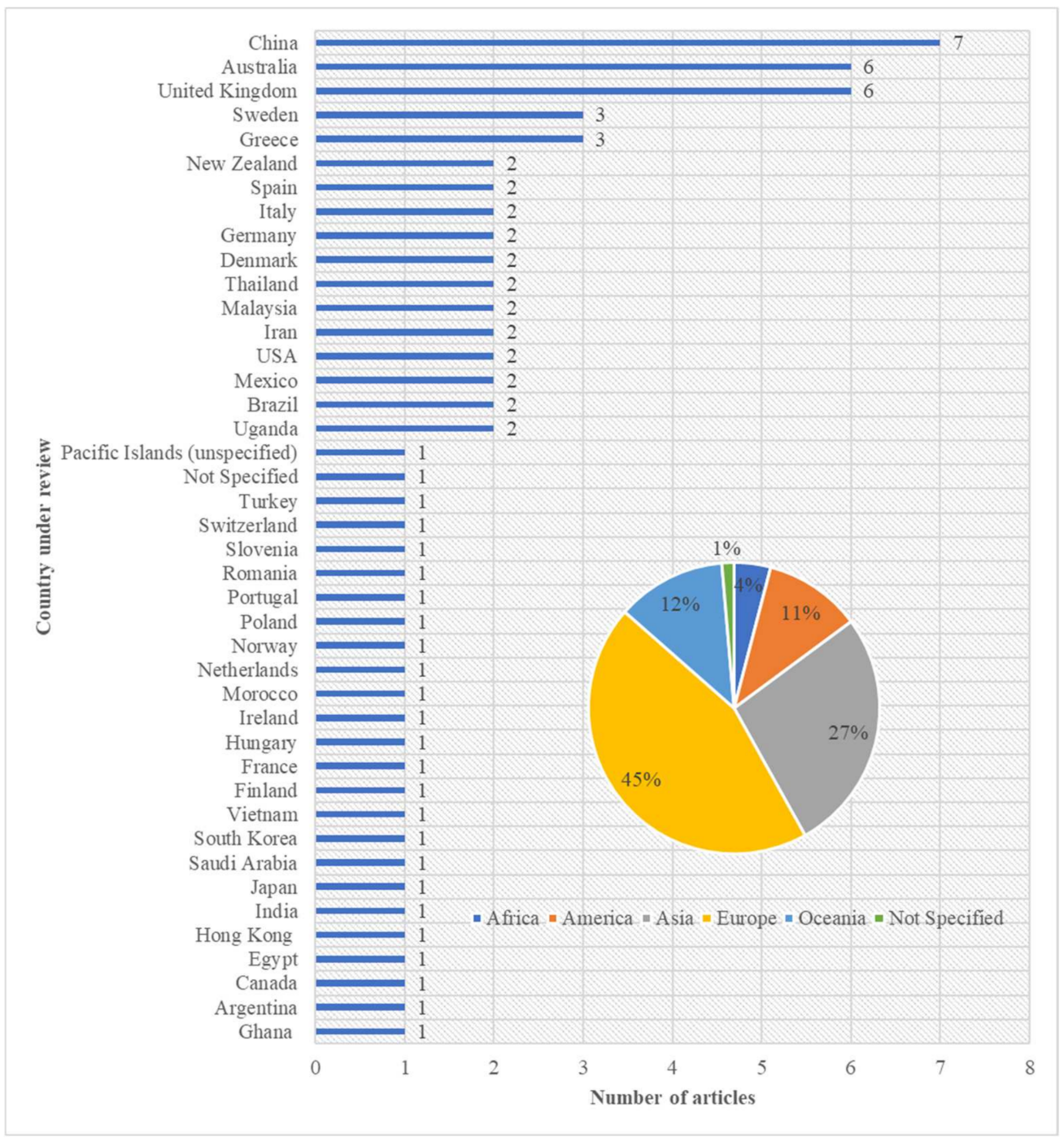

Figure 4. Distribution of papers, based on the country under review.

The climate zone in which each of the studies was carried out is important, as it helps us determine if climate-adaptive measures are suited to the local conditions in the area of study. Figure 5 shows the distribution of selected articles across climate zones according to the Köppen-Geiger climate classification system [44]. Of the 65 articles, 27 were focused on climate-adaptive measures for houses in the $\mathrm{Cfb}$ climate zone, which is described as warm temperate, fully humid, and warm in the summer months. Of the 65, 19 articles reported research undertaken in the Cfa zone (a warm temperate climate, fully humid and with hot summers); 11 in the Aw zone (equatorial and winters that are dry); and 8 in both the BSk zone (arid, steppe, and cold arid conditions) and the Dwa zone (snow, winters that are dry, and hot summers). 


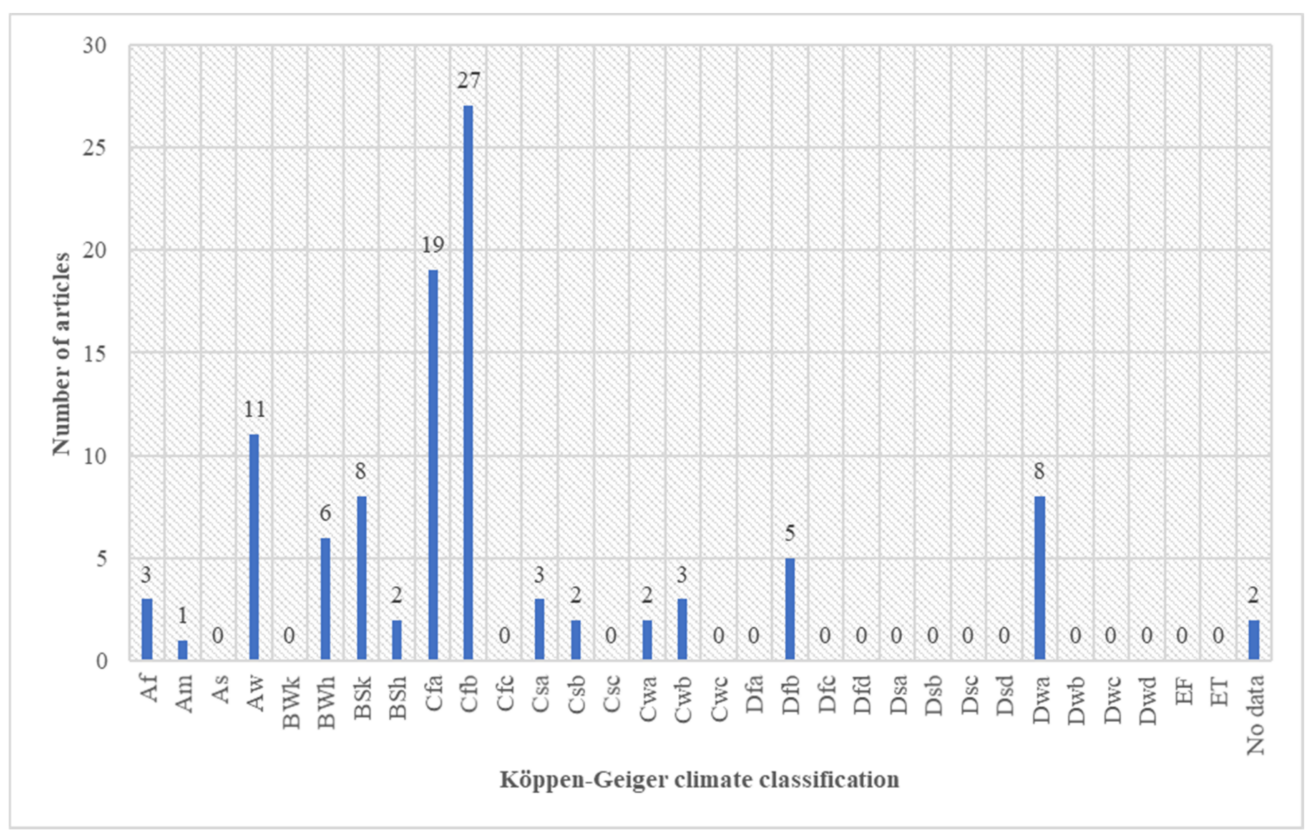

Figure 5. Distribution of papers based on the climate classification (Köppen-Geiger) of the studied region.

\subsection{Climate-Adaptive Measures Related to Housing and Its Categorization}

Across the 65 articles included in this review, a total of 21 climate-adaptive housing measures were identified, falling into three categories, namely, (1) passive design, (2) building technology, and (3) building performance assessment tools. The concept of passive design revolves around utilizing natural heating and cooling sources (e.g., solar heating and cool breezes), building orientation, and the design of the structure, building envelope, and HVAC facilities to achieve indoor thermal comfort, energy efficiency, and a reduction in energy consumption [45]. The building technology category involves the use of different technologies and machinery for improving the condition of residential dwellings with the use of smart and innovative systems. The building performance assessment tool encompasses tools resulting from computational methods, such as simulations, models, and algorithms. It also includes assessment and evaluation tools for optimization, risk profiling, retrofitting, and self-help building. Table 2 shows a list of the 21 measures identified and their categories. Passive design is the most commonly studied approach, mentioned in 38 articles out of $65(58.46 \%)$, followed by building performance assessment tools (18 articles out of $65,27.69 \%$ ), and building technology (9 articles out of 65, 13.85\%). Of the 65 articles, 25 articles considered different design approaches that could impact directly on thermal comfort and energy efficiency, and 14 articles were simulation models.

Among the 65 articles, "design" considerations were the most commonly identified measure, appearing in $38.46 \%$ of the articles. This is not unexpected, as designing for adaptation is seen as a sensible approach toward responding directly to the challenges and opportunities posed by climate change in the future [3]. This measure also showed that designing for adaptation is vital, and that there are different ways of designing for climate adaptability. For instance, some measures were presented as climate-adaptive/climate-responsive designs [3,46,47], some as architectural designs that can be applied to rural residences [48], some as building microclimate designs [49], traditional dwelling designs [50-53], roof designs [54,55], design criteria or regulations [56-58], passive house designs [19,59-61], building envelope designs [62-64], adaptation designs for social housing [65], and some as structural designs [66-68]. 
Table 2. List, description, and distribution of climate-adaptive measures.

\begin{tabular}{|c|c|c|c|c|}
\hline $\begin{array}{l}\text { Category of } \\
\text { Measures }\end{array}$ & Measures [Code] & Description & Count & $\begin{array}{l}\text { Percentage } \\
\quad(\%)\end{array}$ \\
\hline \multirow[t]{8}{*}{$\begin{array}{l}\text { Passive design } \\
(38 \text { articles, } 58.46 \%)\end{array}$} & Design [P1] & $\begin{array}{l}\text { Structural, architectural, or spatial design that considers } \\
\text { passive strategies and climate, aimed at reducing } \\
\text { heating/cooling and energy usage or the production of } \\
\text { climate-adaptive building designs }\end{array}$ & 25 & 38.46 \\
\hline & Paint [P2] & $\begin{array}{c}\text { The use of paint to aid cooling and heating demands of the } \\
\text { building under observation }\end{array}$ & 2 & 3.08 \\
\hline & $\begin{array}{l}\text { Mechanical devices for } \\
\text { heating [P3] }\end{array}$ & $\begin{array}{l}\text { The use of mechanical devices such as district heating } \\
\text { (centralized heating) and individual heating to address } \\
\text { thermal comfort }\end{array}$ & 1 & 1.54 \\
\hline & Ventilation techniques [P4] & $\begin{array}{l}\text { The use of day ventilation, night ventilation, full-day } \\
\text { ventilation, or stack ventilation for indoor cooling }\end{array}$ & 2 & 3.08 \\
\hline & Phase change material [P5] & $\begin{array}{l}\text { A medium that absorbs/releases energy to provide } \\
\text { heating/cooling }\end{array}$ & 1 & 1.54 \\
\hline & $\begin{array}{l}\text { Heat storage wall (made of } \\
\text { concrete and encapsulated } \\
\text { water) [P6] }\end{array}$ & $\begin{array}{l}\text { A heat-storage wall made of concrete and encapsulated water } \\
\text { to provide insulation }\end{array}$ & 1 & 1.54 \\
\hline & Shading [P7] & $\begin{array}{c}\text { Mechanical equipment (e.g., awnings, exterior walls, Venetian } \\
\text { blinds, or overhangs) or natural shading (e.g., trees) that } \\
\text { provides shade and reduces heat gains: provides indoor } \\
\text { comfort in terms of cooling/heating }\end{array}$ & 4 & 6.15 \\
\hline & $\begin{array}{l}\text { Glazing (façade glazing, window } \\
\text { glazing) [P8] }\end{array}$ & $\begin{array}{l}\text { The use of glass or various forms of coated glass to admit light } \\
\text { while controlling heat gain or heat loss for use in insulation }\end{array}$ & 2 & 3.08 \\
\hline \multirow[t]{8}{*}{$\begin{array}{l}\text { Building technology } \\
\text { ( } 9 \text { articles, } 13.85 \%)\end{array}$} & $\begin{array}{l}\text { Climate-adaptive building shells } \\
\text { (façade technology) [B1] }\end{array}$ & $\begin{array}{l}\text { Adaptive façade technology that deals with energy savings } \\
\text { and indoor comfort }\end{array}$ & 1 & 1.54 \\
\hline & Smart Skins [B2] & $\begin{array}{c}\text { Skins for buildings capable of responding to external and } \\
\text { internal conditions and implementing context-aware functions. } \\
\text { Agent-based smart skins that can describe } \\
\text { the state of indoor/outdoor environment and also } \\
\text { prompt users }\end{array}$ & 1 & 1.54 \\
\hline & $\begin{array}{l}\text { Model-predictive heating } \\
\text { controller [B3] }\end{array}$ & $\begin{array}{l}\text { A controller that is non-invasive and has a } \\
\text { model-predictive algorithm for adaptability }\end{array}$ & 1 & 1.54 \\
\hline & Smart Windows [B4] & $\begin{array}{l}\text { Window technology that uses electrochromism (a material able } \\
\text { to switch from transparent to opaque or block all light) to } \\
\text { control or change heat gain, thus reducing the energy needed } \\
\text { for cooling/heating }\end{array}$ & 1 & 1.54 \\
\hline & Solar Chimney [B5] & $\begin{array}{l}\text { Type of passive solar heating and cooling system that can be } \\
\text { used to regulate temperature and natural ventilation }\end{array}$ & 1 & 1.54 \\
\hline & Green Roof [B6] & $\begin{array}{c}\text { A layer of vegetation planted over a roof or part of a roof to } \\
\text { help improve air quality and reduce the heat } \\
\text { island effect }\end{array}$ & 2 & 3.08 \\
\hline & Innovative construction [B7] & $\begin{array}{l}\text { Innovative construction using vapor checking material } \\
\text { combined with a rigid air barrier }\end{array}$ & 1 & 1.54 \\
\hline & $\begin{array}{l}\text { Solar Source Heat-Pump } \\
\text { System [B8] }\end{array}$ & $\begin{array}{c}\text { A system or machine in which there is a combination } \\
\text { or integration of a solar source (solar panels) and a } \\
\text { heat pump }\end{array}$ & 1 & 1.54 \\
\hline \multirow[t]{5}{*}{$\begin{array}{c}\text { Building } \\
\text { performance } \\
\text { assessment tools } \\
(18 \text { articles, } 27.69 \%)\end{array}$} & $\begin{array}{l}\text { Assessment tool for } \\
\text { self-help housing [T1] }\end{array}$ & $\begin{array}{l}\text { Low-carbon and disaster-resilient assessment tools for } \\
\text { self-help housing }\end{array}$ & 1 & 1.54 \\
\hline & Simulation tools [T2] & $\begin{array}{c}\text { A tool based on computational methods such as simulation, } \\
\text { modeling, algorithms, computer programs } \\
\text { and software }\end{array}$ & 14 & 21.54 \\
\hline & Computational platforms [T3] & $\begin{array}{l}\text { A general computational procedure associated with optimal } \\
\text { adaptation strategies }\end{array}$ & 1 & 1.54 \\
\hline & Web-based retrofit toolkit [T4] & $\begin{array}{l}\text { A web-based toolkit that provides holistic retrofit guidance for } \\
\text { designers, homeowners, and decision-makers }\end{array}$ & 1 & 1.54 \\
\hline & Risk profiling [T5] & $\begin{array}{c}\text { A risk distribution approach to assess risk profiles in risk } \\
\text { distributions }\end{array}$ & 1 & 1.54 \\
\hline Total & & & 65 & 100.00 \\
\hline
\end{tabular}

It is interesting to note that the design used in traditional dwellings can sometimes be incorporated effectively into the creation of modern buildings, as in the case of the studies carried out by Chi et al. [48] and Juan et al. [52]. Additionally, designing for climate adaptation not only covers the indoor environment or the building per se, but it may be 
applicable to outdoor environments as well. As illustrated by Hosham and Kubota [49], the design of the microclimate also affects indoor conditions (e.g., temperature and shading). This could be improved by the incorporation of natural shading sources, such as trees and vegetation or water spraying.

Other climate-adaptive measures that fall under the passive design category, such as shading, ventilation, glazing, specific materials (e.g., paints, phase change materials, and heat storage walls), and mechanical devices for heating and cooling, were also recognized. Shading and glazing utilize natural sources of heat (i.e., solar energy) and shade (i.e., trees and vegetation) to attain desirable indoor conditions [69-71], while ventilation measures take advantage of natural breezes for improving indoor air circulation [72,73]. Additionally, specific materials and mechanical devices can both contribute by addressing those problems related to heat gains and heating and cooling demands [74-78]. The majority, if not all, of these measures are implemented for the whole house since they mostly deal with indoor comfort. Although all of these measures lead to the fulfillment of the goals of passive design, it should be remembered that most measures from this category need to be applied as early as possible at the pre-design stage. In cases where houses have already been built, there are also ways for these to be retrofitted or improved, although a drawback is that this might incur high costs [64].

On the other hand, the building technology category presented advanced climateadaptive measures for housing, consisting of smart technologies aimed at specific parts of the dwelling unit. For instance, green roofs are found to contribute to energy savings in the house by providing insulation, thus reducing the heating demands of buildings $[79,80]$; while climate-adaptive building shells are expected to offer better energy performance as well as daylight illumination [81]. The only measure that considered the user experience, together with environmental parameters, was conducted by Chen and Chiu [21] in the context of smart skins; smart windows, solar chimneys, solar-source heat pump systems, and model-predictive heating controllers are all dependent on external factors (i.e., environmental parameters) [22,82-84].

The building performance assessment tools category comprised computational methods and software for illustrating climate-adaptive measures. The simulation tools, showing different housing scenarios under different situations or climate conditions, were the most popular measure in this category. Aside from simulation tools, one of the measures identified in this category is the assessment tool for self-help housing. This measure showed that the climate-adaptability of homes should not only cover houses built by builders but also dwelling units built by the users themselves. This can be expected to be of most relevance to developing nations, where not all have the capability to hire designers and builders [20]. Another measure identified from this category that seems important when dealing with climate-adaptivity, in particular, is risk profiling [85]. The knowledge developed from conducting this measure can eventually facilitate better decision-making processes for adapting to local climate under conditions of considerable uncertainty.

\subsection{Benefits of Adopting Climate-Adaptive Measures}

Ten benefits, based on the implementation of the different measures, were identified from the 65 reviewed articles. These are listed in Table 3. The benefit most frequently noted in these articles is improved thermal comfort at $50.76 \%$, among which articles $16.67 \%$ are in relation to reduced heat gain. This is followed by energy efficiency at $26.52 \%$. This could be linked to the fact that the majority of the measures fall under passive design, which means that they are aimed at achieving a comfortable temperature at a low level of energy consumption. In addition, cost efficiency, improved shading and illumination, and reduced carbon emission each hold a $4.55 \%$ share, while an improved hygrothermal condition is at $3.04 \%$. The remaining $6.03 \%$ comes from disaster resilience, visual satisfaction, optimal adaptation planning, and smart-user-experience-oriented measures. Often, multiple benefits have been shown to arise from an identified measure; for instance, the use of a certain 
paint on the roof can result in benefits such as reduced heat gains, energy efficiency, and visual satisfaction [75].

Table 3. Distribution of papers based on the benefits of applying the measures.

\begin{tabular}{ccc}
\hline Benefit & Count & Percentage (\%) \\
\hline Improved thermal comfort & 12 & 9.09 \\
Improved insulation & 7 & 5.30 \\
Improved ventilation & 22 & 16.67 \\
Reduced heat gain & 15 & 11.36 \\
Reduced heating/cooling demand & 6 & 4.55 \\
Reduced risk of overheating & 5 & 3.79 \\
Improved indoor air temperature & 35 & 26.52 \\
\hline Energy efficiency & 6 & 4.55 \\
\hline Cost efficiency & 6 & 4.55 \\
\hline Improved shading and illumination & 6 & 4.55 \\
\hline Reduced carbon emission & & 1.52 \\
\hline Improved hygrothermal condition & 2 & 1.52 \\
Reduced risk of mold growth & 2 & 3.03 \\
Reduced condensation & 4 & 1.52 \\
\hline Disaster resilience & 2 & 0.76 \\
\hline Visual satisfaction & 1 & 0.76 \\
\hline Optimal adaptation plan & 1 & 100.00 \\
\hline Smart user experience-oriented & 132 & \\
\hline Total & & \\
\hline
\end{tabular}

Table 4 illustrates the relationship between climate-adaptive measures and the benefits associated with the adoption of each of these measures under different scenarios. Each climate-adaptive measure is represented by codes (as listed in Table 2), and the frequency of occurrence per benefit that arises from it is shown as "number $\times$ code" (e.g., $7 \times \mathrm{P} 1$ means that this benefit arose 7 times using P1).

From this table, it is apparent that design P1 leads, in terms of the number of benefits that have been identified from it (59 occurrences out of 132). It is recorded that if P1 is implemented, the following benefits could be derived: energy efficiency ( 15 articles), reduced heat gain (10 articles), improved insulation ( 7 articles), reduced heating/cooling demand ( 6 articles), improved ventilation ( 5 articles), improved shading and illumination ( 4 articles), cost efficiency ( 3 articles), reduced risk of overheating ( 2 articles), improved indoor temperature ( 2 articles), reduced carbon emission ( 2 articles), disaster resilience ( 2 articles), and reduced condensation ( 1 article). The majority of the benefits from P1 are related to improved thermal comfort, which again draws back to the main goal of passive designs - maintaining the dwelling at a comfortable temperature while minimizing energy consumption. The second most frequent simulation tool identified is T2 (23 occurrences out of 132). When T2 is implemented, the following benefits could be derived from it: energy efficiency ( 8 articles), reduced heating/cooling demand (4 articles), improved insulation ( 3 articles), reduced risk of overheating ( 2 articles), reduced carbon emission ( 2 articles), reduced heat gain, improved ventilation, cost efficiency, and a reduced risk of mold growth ( 1 article each). For T2, energy efficiency is the benefit that has been identified the most often. This can be attributed to the fact that most developed computational methods and software aim to simulate how households can reduce energy consumption. 
Table 4. Relationship between climate-adaptive measures and the benefits of adopting these measures.

\begin{tabular}{|c|c|c|c|}
\hline Benefit & Measure Adopted Resulting to Benefit & Count & Percentage $(\%)$ \\
\hline \multicolumn{4}{|l|}{ Improved thermal comfort } \\
\hline Improved insulation & $7 \times \mathrm{P} 1, \mathrm{~B} 3, \mathrm{~B} 6,3 \times \mathrm{T} 2$ & 12 & 9.09 \\
\hline Improved ventilation & $5 \times \mathrm{P} 1, \mathrm{P} 4, \mathrm{~T} 2$ & 7 & 5.30 \\
\hline Reduced heat gain & $\begin{array}{c}10 \times \mathrm{P} 1,2 \times \mathrm{P} 2, \mathrm{P} 6,2 \times \mathrm{P} 7,2 \times \mathrm{P} 8, \mathrm{~B} 1, \mathrm{~B} 4, \mathrm{~B} 6, \\
\mathrm{~T} 2, \mathrm{~T} 4\end{array}$ & 22 & 16.67 \\
\hline Reduced heating/cooling demand & $6 \times \mathrm{P} 1, \mathrm{P} 3, \mathrm{P} 7, \mathrm{P} 8, \mathrm{~B} 7,4 \times \mathrm{T} 2, \mathrm{~T} 4$ & 15 & 11.36 \\
\hline Reduced risk of overheating & $2 \times \mathrm{P} 1, \mathrm{P} 7,2 \times \mathrm{T} 2, \mathrm{~T} 4$ & 6 & 4.55 \\
\hline Improved indoor air temperature & $2 \times \mathrm{P} 1, \mathrm{P} 4, \mathrm{P} 5, \mathrm{~B} 8$ & 5 & 3.79 \\
\hline Energy efficiency & $\begin{array}{c}15 \times \mathrm{P} 1,2 \times \mathrm{P} 2, \mathrm{P} 3,2 \times \mathrm{P} 6,2 \times \mathrm{P} 7, \mathrm{~B} 1, \mathrm{~B} 3, \mathrm{~B} 5 \\
\mathrm{~B} 6,8 \times \mathrm{T} 2, \mathrm{~T} 4\end{array}$ & 35 & 26.52 \\
\hline Cost efficiency & $3 \times \mathrm{P} 1, \mathrm{P} 6, \mathrm{~T} 1, \mathrm{~T} 2$ & 6 & 4.55 \\
\hline Improved shading and illumination & $4 \times \mathrm{P} 1, \mathrm{P} 7, \mathrm{~B} 1$ & 6 & 4.55 \\
\hline Reduced carbon emission & $2 \times \mathrm{P} 1, \mathrm{~B} 5, \mathrm{~T} 1,2 \times \mathrm{T} 2$ & 6 & 4.55 \\
\hline \multicolumn{4}{|l|}{ Improved hygrothermal condition } \\
\hline Reduced risk of mold growth & $\mathrm{B} 7, \mathrm{~T} 2$ & 2 & 1.52 \\
\hline Reduced condensation & P1, B7 & 2 & 1.52 \\
\hline Disaster resilience & $2 \times \mathrm{P} 1, \mathrm{~T} 1, \mathrm{~T} 5$ & 4 & 3.03 \\
\hline Visual satisfaction & $2 \times \mathrm{P} 2$ & 2 & 1.52 \\
\hline Optimal adaptation plan & $\mathrm{T} 3$ & 1 & 0.76 \\
\hline Smart user experience-oriented & B2 & 1 & 0.76 \\
\hline Total & & 132 & 100.00 \\
\hline
\end{tabular}

\section{Discussion}

The results of the passive design categorization showed that, while designing for adaptation is vital, it is also important that adaptation strategies for buildings suit the needs of the occupants, unlike the one-size-fits-all design for adaptability that is currently the most common approach being taken [3]. In some cases, while the design may meet set guidelines, it may not be entirely suitable for the occupants throughout the building's lifetime. Aside from meeting the occupants' needs, another consideration with respect to adaptability is its suitability for the local conditions at the time, and also for future climate conditions for the area. Thus, a useful approach that has been suggested is the establishment of pilot projects for demonstrating the effectiveness of a measure or strategy in the context of the local conditions [19]. This could be highly worthwhile for helping to raise awareness among the public, as well as housing developers and homeowners, of the long-term benefits of using these climate adaptation measures [19].

There are smart innovations or sustainable measures in the building technology category that are ingenious and can be used in a specific component of a house (e.g., windows, walls, façades, and roofs). However, while these technologies are innovative, there is a lack of research focusing on user-oriented mechanisms (a tailored fit to a user's preference) [86]. Furthermore, climate-adaptive measures in the building performance assessment tools category demonstrated that, by using the vast range of computational methods and software available, it is possible to assess the performance of these measures under future scenarios. For instance, simulation using a range of software packages can be used to assess the expected level of indoor thermal comfort under both current and forecasted future climate conditions [87]. Other monitoring devices can assess existing building conditions to identify suitable climatic and architectural solutions for improving design and for use in retrofitting [88,89]. Advanced computation can also analyze specific adaptive measures under different climate projections [90,91], or performing cost-benefit analyses for the implementation of planned adaptation measures [4]. 
To further illustrate, in Sehizadeh et al. [92], the durability of wall materials used in Montréal, Canada was able to be tested for the risk of brick frost damage, plywood decay, and mold growth based on climate predictions for the local conditions. Similarly, in a case study carried out by Wang et al. [85], risk profiling was used to help in decisionmaking for adapting coastal residential buildings to future climate change. The use of retrofit toolkits $[93,94]$ for example, has also been found to be helpful in identifying suitable retrofitting measures in different climate scenarios for older or already-built residences. These tools can assist in informed decision-making, either in the design phase, when renovating, or when future-proofing existing buildings.

It is imperative that a good combination of the abovementioned climate-adaptive measures are considered to ensure that new problems do not arise as a result of the implementation of these measures. For example, the London case study reported on by Makantasi and Mavrogianni [65] noted that under a high emission scenario, unventilated flats (apartments) can be expected to overheat, while flats with natural ventilation would be able to keep the period of overheating to an acceptable level. In addition, walls with internally applied insulation, combined with low ventilation, could also result in a higher chance of overheating in the future [65]. Likewise, while shading reduces overheating in the summer, it increases the winter heating demand $[90,95]$. These examples illustrate the importance of having a good set of climate-adaptive measures to achieve the benefits desired by homeowners over a range of climate conditions.

This systematic review has identified 10 benefits (16, if improved thermal comfort and improved hygrothermal conditions are divided into sub-categories) from the adoption of climate-adaptive measures. The majority of the articles reviewed, however, seem to address problems concerning thermal comfort and energy consumption. Upon looking into the connections between the measures and benefits identified, it is implied that the benefits resulting from climate-adaptive measures are not always the same-they vary depending on the climate zone of the study area or on the different circumstances in their local setting $[48,62]$.

\section{A Conceptual Framework of Climate-Adaptive Housing Measures}

Figure 6 shows a framework of climate-adaptive housing measures, based on the result of this review. The three categories of climate-adaptive measures and their corresponding key measures, which are available for people to use, are illustrated. All three categories are directed towards climate-adaptive houses and are enclosed in a box indicating that these measures, if implemented, may lead to a climate-adaptive house. The border shows that the measures may be related to each other, or may be implemented simultaneously or in combination with one another. It is worth noting that the building performance assessment tools category has arrows directed at the passive design and building technology categories. This shows that the building performance assessment tools may also be used to evaluate the other two categories when implemented and may serve as a way to determine in what areas and how the climate-adaptability of houses can be improved. For example, simulations that determine and predict cooling/heating loads and energy consumption can be run based on the ventilation design of the house [58], which can be used to further assess if the design will meet the standards as set, or if improvements need to be made. To further illustrate, in the study conducted by Gaspari et al. [81] on climate-adaptive building shells, it was found that there is room for future developments in terms of combining optimization criteria and energy-related indicators. This can be initiated by simulating different scenarios based on the current findings. 


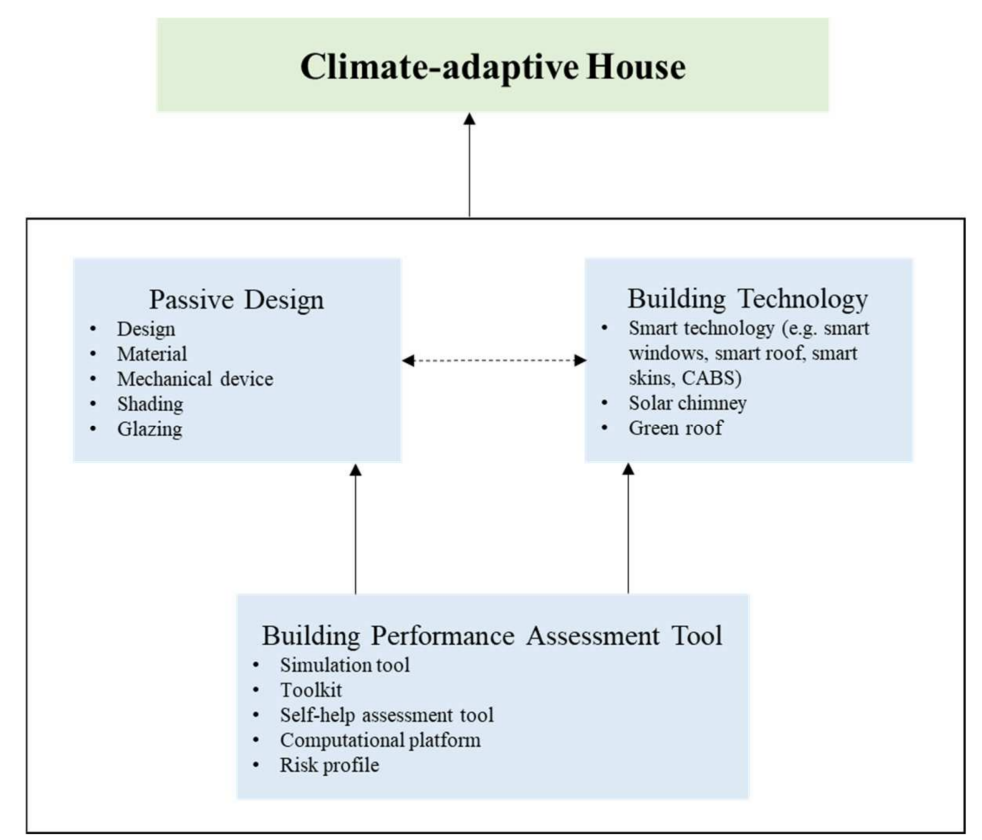

Figure 6. A framework of climate-adaptive housing measures.

Adaptation is a process that involves not only the users (i.e., residents/homeowners) but also other stakeholders (i.e., policymakers, governmental agencies, non-governmental organizations, designers/constructors/developers) [25]. This framework is a useful approach to mapping, collating, and identifying and filling information gaps associated with the climate-adaptive measures available for houses. Moreover, aside from meeting information needs, engaging stakeholders in the adaptation process is preferable because they are the ones responsible for making decisions, and identifying solutions, and policies [96]. To be able to achieve a climate-adaptive house, a collaboration between the different stakeholders is needed. This often includes understanding the relationship between various stakeholders working across sectors, and building networks [97].

By using this framework, the different stakeholders will also be able to recognize the connections between them. Firstly, users will be able to understand the available measures and identify the most promising measures. Upon identification, professional housing providers (i.e., design/architectural firms, engineers) will be able to assess the feasibility of these measures based on the users' specific conditions (i.e., location, adaptive capacity, budget, current house condition) and may be able to further suggest what might work better for their particular situation. Hence, the users and housing providers would have effective communication over the process, leading to more influential outcomes. Secondly, although not directly involved in building climate-adaptive houses, government agencies, policymakers, non-governmental organizations, and even private sectors would also have some control or provide input during the process. These stakeholders provide important resources and lobby agendas related to climate adaptation. Through them, the policies, guidelines, programs, and action plans are realized and implemented. Lastly, another set of stakeholders, such as regulatory bodies, the general public, the media, and other suppliers related to climate-adaptive housing projects also play a part in the process. Even though they are also not involved directly, their undertakings and proficiencies are part of what develops the structure of the projects.

The climate-adaptive measures presented in the framework are solutions that are straightforward. They can be tested scientifically with a combination of local knowledge and experience. However, their success is also dependent on the strength of networks, the knowledge and resources, and the ingenuity of the stakeholders involved in the process. The framework can also work as the first step in identifying climate-adaptive measures and conducting further assessments to identify the right combination to address a particular 
challenge. Ultimately, new technologies and strategies could branch out from the measures identified, as a result of being more proactive in searching for solutions for improving the climate adaptability of homes.

\section{Conclusions}

There is a pressing need for the built environment to adapt to a changing climate. The establishment of different initiatives to demonstrate the science-based evidence of the changing global climate, and its effect on the built environment, presents us with both challenges and opportunities. This article has identified, categorized, and analyzed the different climate-adaptive measures that are currently available, the areas in which these measures have been implemented, and the benefits of adopting them. Among the 65 articles reviewed, 21 climate-adaptive measures were identified and classified into three categories. The majority fell into passive design (the first category) which aims to achieve a comfortable temperature while minimizing energy consumption and are usually measures that are implemented across the house as a whole. The other two categories were building technology and building performance assessment tools, generally implemented in a more specific area of the house such as in the roofs, walls, windows, or in a façade. When compared to passive design, it is noticeable that the building technology category lags behind the others. There are 10 benefits that arise from the identified climate-adaptive measures, two of which could be further split into sub-categories, resulting in 16 distinct benefits. The majority of the benefits are related to improved thermal comfort and energy efficiency.

The findings of this study show that there are already many initiatives in place aimed at making houses climate-adaptive. These efforts in research are probably driven by factors such as the political context, sustainable development goals [98], or science-based evidence of changes in the climate (e.g., global warming and GHG emissions). Arguably, there is still room for improvement when it comes to these measures.

Based on the current literature, this topic is globally emerging. There might be concepts that are not yet clearly defined for all to have a similar understanding, and for others, there are no sets of standards or rules to follow when it comes to adaptability and adaptive capacity. Ideas may still be in a one-size-fits-all methodology, which is not ideal for climate adaptivity since it should suit the needs of the occupant and match the local climate of the area. This review can serve as baseline data for such identified climate-adaptive measures, and stakeholders can use it to check if the identified measures are applicable in their own local conditions or studies. They can also use it as a basis for developing policies or technologies for climate-adaptive housing.

Even though the investigation of 65 articles casts light on the different climate-adaptive measures currently in place, this review also has its limitations. The examination focused solely on environmental changes, particularly rising temperature brought about by climate. It also did not specify the type of housing studied and did not incorporate any stakeholder analysis. Moreover, while the authors acknowledge that there is a wide body of literature addressing climate-adaptive measures for housing, including influential books, as well as guidance on regulations and standards, these may not have been captured in the review due to the search criteria imposed. Future studies could include other effects of climate change (i.e., flooding and bushfire), and environmental changes brought about by factors other than climate (i.e., pollution, urban sprawl, waste production, and ozone depletion). Moving forward, this paper could lead to other research, including the tailoring of smart technology to suit the user's needs. When it comes to making a house climate-adaptive, studies localizing climate-adaptive measures are important, avoiding the assumption that these measures work equally well under different climate conditions. The performance of the measures could also be investigated for buildings that are non-residential (e.g., commercial spaces, offices, and schools).

It is evident from this review that there remains little exploration into smart technologies that can be applied to achieve climate adaptability of housing to meet occupants' 
specific needs. The bulk of the building technologies implemented at present (e.g., smart windows, smart roofs, etc.) are used in response to external factors, such as the weather or microclimate, or to improve the indoor conditions. In this regard, customizing smart technology to the needs (and possibly the wants) of a user, in the context of climate-adaptive housing, is an opportunity for further research. In addition, localizing climate-adaptive measures based on the geographical areas of potential climate-adaptive housing systems is critical. Another challenge identified in the review is the lack of clarity around the roles played by various stakeholders (i.e., owner, designer/constructor/developer, policymaker, housing agency, and investor) in addressing the climate-adaptability of houses. A closer look at stakeholders' tasks regarding this topic would be beneficial in creating a more comprehensive list of what needs to be done to break out and redefine boundaries and responsibilities for creating climate-adaptive houses. Some countries already have policies in place for climate change adaptation and mitigation, based on their climate action or climate agenda. However, there is still room for improvement, especially with regard to the roles of stakeholders and when creating, updating, or implementing policies.

Author Contributions: Conceptualization, M.K.R. and A.C.-R.; methodology, M.K.R. and A.C.-R.; validation, M.K.R., A.C.-R., K.I.-K.W. and K.N.D.; formal analysis, M.K.R.; investigation, M.K.R.; writing-original draft preparation, M.K.R.; writing—review and editing, M.K.R., A.C.-R., K.I.-K.W. and K.N.D.; supervision, A.C.-R., K.I.-K.W. and K.N.D. All authors have read and agreed to the published version of the manuscript.

Funding: The first author acknowledges support and funding from the awarding of a University of Auckland Doctoral Scholarship.

Institutional Review Board Statement: Not applicable.

Informed Consent Statement: Not applicable.

Data Availability Statement: The data presented in this study are available on request from the corresponding author.

Conflicts of Interest: The authors declare no conflict of interest.

\section{References}

1. UN OHCHR. The Right to Adequate Housing; UN Office of the High Commissioner for Human Rights: Geneva, Switzerland, 2009.

2. Agbola, T. The Housing of Nigerians: A Review of Policy Development and Implementation; Development Policy Centre: Canberra, Australia, 1998.

3. Kinnane, O.; Grey, T.; Dyer, M. Adaptable housing design for climate change adaptation. Proc. Inst. Civ. Eng. Eng. Sustain. 2017, 170, 249-267. [CrossRef]

4. Ren, Z.; Chen, Z.; Wang, X. Climate change adaptation pathways for Australian residential buildings. Build. Environ. 2011, 46, 2398-2412. [CrossRef]

5. Bengtsson, J.; Hargreaves, R.; Page, I.C. Assessment of the Need to Adapt Buildings in New Zealand to the Impacts of Climate Change; BRANZ: Porirua, New Zealand, 2007; Volume 179, pp. 63-70.

6. IPCC. Global Warming of $1.5^{\circ} \mathrm{C}$. An IPCC Special Report on the Impacts of Global Warming of $1.5^{\circ} \mathrm{C}$ above Pre-Industrial Levels and Related Global Greenhouse Gas Emission Pathways, in the Context of Strengthening the Global Response to the Threat of Climate Change; Intergovernmental Panel on Climate Change: Geneva, Switzerland, 2018.

7. Stewart, M.G. Risk and economic viability of housing climate adaptation strategies for wind hazards in southeast Australia. Mitig. Adapt. Strateg. Glob. Chang. 2015, 20, 601-622. [CrossRef]

8. Chalmers, P. Climate Change: Implication for Buildings. Key findings from the Intergovernmental Panel on Climate Change Fifth Assessment Report; European Climate Foundation (ECF); Buildings Performance Institute Europe (BPIE); Global Buildings Performance Network (GBPN); World Business Council for Sustainable Development (WBCSD); University of Cambridge's Judge Business School (CJBS); Institute for Sustainability Leadership (CISL): Cambridge, UK, 2014.

9. Maller, C.J.; Strengers, Y. Housing, heat stress and health in a changing climate: Promoting the adaptive capacity of vulnerable households, a suggested way forward. Health Promot. Int. 2011, 26, 492-498. [CrossRef]

10. Lacasse, M.; Gaur, A.; Moore, T. Durability and Climate Change-Implications for Service Life Prediction and the Maintainability of Buildings. Buildings 2020, 10, 53. [CrossRef]

11. EM-DAT. EM-DAT: The Emergency Events Database—Université Catholique de Louvain (UCL)—CRED, D. Guha-Sapir. Available online: www.emdat.be (accessed on 12 January 2021). 
12. UN Environment and International Energy Agency. Towards a Zero-Emission, Efficient, and Resilient Buildings and Construction Sector. Global Status Report 2017; United Nations Environment Programme: Paris, France, 2017; pp. 20-35.

13. Dave, M.; Varshney, A.; Graham, P. Assessing the Climate Change Adaptability of Buildings; National Climate Change Adaptation Research Facility: Gold Coast, Australia, 2012.

14. IPCC. Climate Change 2014: Synthesis Report. Contribution of Working Groups I, II, and III to the Fifth Assessment Report of the Intergovernmental Panel on Climate Change; Pachauri, R.K., Meyer, L.A., Eds.; Intergovernmental Panel on Climate Change: Geneva, Switzerland, 2014.

15. UNEP. Mitigation Refers to Management Practices or Consumer Behavior. UNEP Climate Change Mitigation. Available online: https:/ / www.unenvironment.org/explore-topics/climate-change/what-we-do/mitigation\#: \{\}:text=ClimateChange (accessed on 1 June 2020).

16. UNDP. UNDP Climate Change Adaptation. Available online: https://www.adaptation-undp.org/about (accessed on 1 May 2020).

17. Yilmaz, M.; Keleş, R. Sustainable housing design and the natural environment. Ekistics 2004, 71, $236-243$.

18. Gupta, R. Moving towards low-carbon buildings and cities: Experiences from Oxford, UK. Int. J. Low Carbon Technol. 2009, 4, 159-168. [CrossRef]

19. Dan, D.; Tanasa, C.; Stoian, V.; Brata, S.; Stoian, D.; Nagy Gyorgy, T.; Florut, S.C. Passive house design-An efficient solution for residential buildings in Romania. Energy Sustain. Dev. 2016, 32, 99-109. [CrossRef]

20. Charoenkit, S.; Kumar, S. Building low-carbon and disaster-resilient communities: Integrating climate mitigation and adaptation into the assessment of self-help housing design. Mitig. Adapt. Strateg. Glob. Chang. 2017, 22, 695-728. [CrossRef]

21. Chen, S.-Y.; Chiu, M.-L. Designing Smart Skins for Adaptive Environments: A fuzzy logic approach to smart house design. Comput. Aided Des. Appl. 2007, 4, 751-760. [CrossRef]

22. Javad, K.; Navid, G. Thermal comfort investigation of stratified indoor environment in displacement ventilation: Climate-adaptive building with smart windows. Sustain. Cities Soc. 2019, 46, 101354. [CrossRef]

23. Obrecht, T.P.; Premrov, M.; Leskovar, V.Ž. Influence of the orientation on the optimal glazing size for passive houses in different European climates (for non-cardinal directions). Sol. Energy 2019, 189, 15-25. [CrossRef]

24. Sghiouri, H.; Mezrhab, A.; Karkri, M.; Naji, H. Shading devices optimization to enhance thermal comfort and energy performance of a residential building in Morocco. J. Build. Eng. 2018, 18, 292-302. [CrossRef]

25. Martin, C.; Campillo, G.; Meirovich, H.; Navarrete, J. Climate Change Mitigation and Adaptation Through Publically-Assisted Housing. Theoretical Framework for the IDB's Regional Policy Dialogue on Climate Change; Inter-American Development Bank: Washington, DC, USA, 2013.

26. Ozay, N. A comparative study of climatically responsive house design at various periods of Northern Cyprus architecture. Build. Environ. 2005, 40, 841-852. [CrossRef]

27. Pomponi, F.; Moncaster, A. Embodied carbon mitigation and reduction in the built environment-What does the evidence say? J. Environ. Manag. 2016, 181, 687-700. [CrossRef]

28. Iyendo, T.; Akngbaso, E.; Alibaba, H.; Özdeniz, M. A relative study of microclimate responsive design approaches to buildings in Cypriot settlements. A IZ ITU J. Fac. Archit. 2016, 13, 69-81. [CrossRef]

29. Meir, I.A.; Pearlmutter, D. Building for climate change: Planning and design considerations in time of climatic uncertainty. Corros. Eng. Sci. Technol. 2010, 45, 70-75. [CrossRef]

30. Klein, R.J.T.; Huq, S.; Denton, F.; Downing, T.E.; Richels, R.G.; Robinson, J.B.; Toth, F.L. 2007: Inter-Relationships between Adaptation and Mitigation, Climate Change 2007: Impacts, Adaptation and Vulnerability. Contribution of Working Group II to the Fourth Assessment Report of the Intergovernmental Panel on Climate Change; Cambridge University Press: Cambridge, UK, 2007; pp. $745-777$.

31. Askie, L.; Offringa, M. Systematic reviews and meta-analysis. Semin. Fetal Neonatal Med. 2015, 20, 403-409. [CrossRef] [PubMed]

32. Tranfield, D.; Denyer, D.; Smart, P. Towards a Methodology for Developing Evidence-Informed Management Knowledge by Means of Systematic Review. Br. J. Manag. 2003, 14, 207-222. [CrossRef]

33. Ayodele, O.A.; Chang-Richards, A.; González, V. Factors Affecting Workforce Turnover in the Construction Sector: A Systematic Review. J. Constr. Eng. Manag. 2020, 146, 03119010. [CrossRef]

34. Pomponi, F.; Piroozfar, P.A.E.; Southall, R.; Ashton, P.; Farr, E.R.P. Energy performance of Double-Skin Façades in temperate climates: A systematic review and meta-analysis. Renew. Sustain. Energy Rev. 2016, 54, 1525-1536. [CrossRef]

35. Aquilani, B.; Silvestri, C.; Ruggieri, A.; Gatti, C. A systematic literature review on total quality management critical success factors and the identification of new avenues of research. TQM J. 2017, 29, 184-213. [CrossRef]

36. Kitchenham, B.; Pearl Brereton, O.; Budgen, D.; Turner, M.; Bailey, J.; Linkman, S. Systematic literature reviews in software engineering-A systematic literature review. Inf. Softw. Technol. 2009, 51, 7-15. [CrossRef]

37. Moher, D.; Shamseer, L.; Clarke, M.; Ghersi, D.; Liberati, A.; Petticrew, M.; Shekelle, P.; Stewart, L. Preferred reporting items for systematic review and meta-analysis protocols (PRISMA-P) 2015 statement. Syst. Rev. 2015, 4, 1-9. [CrossRef]

38. Saieg, P.; Sotelino, E.D.; Nascimento, D.; Caiado, R.G.G. Interactions of Building Information Modeling, Lean and Sustainability on the Architectural, Engineering and Construction industry: A systematic review. J. Clean. Prod. 2018, 174, 788-806. [CrossRef]

39. Shamseer, L.; Moher, D.; Clarke, M.; Ghersi, D.; Liberati, A.; Petticrew, M.; Shekelle, P.; Stewart, L.A. Preferred reporting items for systematic review and meta-analysis protocols (PRISMA-P) 2015: Elaboration and explanation. BMJ Clin. Res. Ed. 2015, 349, g7647. [CrossRef]

40. Aghaei Chadegani, A.; Salehi, H.; Md Yunus, M.; Farhadi, H.; Fooladi, M.; Farhadi, M.; Ale Ebrahim, N. A comparison between two main academic literature collections: Web of science and scopus databases. Asian Soc. Sci. 2013, 9, 18-26. [CrossRef] 
41. Royle, P.; Kandala, N.-B.; Barnard, K.; Waugh, N. Bibliometrics of systematic reviews: Analysis of citation rates and journal impact factors. Syst. Rev. 2013, 2, 74. [CrossRef] [PubMed]

42. Guerrero-Bote, V.; Moya-Anegon, F. A further step forward in measuring journals' scientific prestige: The SJR2 indicator. J. Informetr. 2012, 6, 674-688. [CrossRef]

43. Lee Abbott, M.; McKinney, J. Content Analysis; John Wiley \& Sons, Inc.: Hoboken, NJ, USA, 2013; pp. $316-325$.

44. Peel, M.C.; Finlayson, B.L.; McMahon, T.A. Updated world map of the Köppen-Geiger climate classification. Hydrol. Earth Syst. Sci. 2007, 11, 1633-1644. [CrossRef]

45. Rodriguez-Ubinas, E.; Montero, C.; Porteros, M.; Vega, S.; Navarro, I.; Castillo-Cagigal, M.; Matallanas, E.; Gutiérrez, A. Passive design strategies and performance of Net Energy Plus Houses. Energy Build. 2014, 83, 10-22. [CrossRef]

46. Keeffe, G.; McHugh, I. IDEAhaus: A Modular Approach to Climate Resilient UK Housing. Buildings 2014, 4, 661-682. [CrossRef]

47. Sun, F. Achieving suitable thermal performance in residential buildings in different climatic regions of China. Energy Build. 2013, 67, 11-21. [CrossRef]

48. Chi, F.A.; Borys, I.; Jin, L.; Zhu, Z.; Bart, D. The strategies and effectiveness of climate adaptation for the thousand pillars dwelling based on passive elements and passive spaces. Energy Build. 2019, 183, 17-44. [CrossRef]

49. Hosham, A.F.; Kubota, T. Effects of Building Microclimate on the Thermal Environment of Traditional Japanese Houses during Hot-Humid Summer. Buildings 2019, 9, 22. [CrossRef]

50. Blázquez, T.; Ferrari, S.; Suárez, R.; Sendra, J.J. Adaptive approach-based assessment of a heritage residential complex in southern Spain for improving comfort and energy efficiency through passive strategies: A study based on a monitored flat. Energy 2019, 181, 504-520. [CrossRef]

51. Gou, S.; Li, Z.; Zhao, Q.; Nik, V.M.; Scartezzini, J.-L. Climate responsive strategies of traditional dwellings located in an ancient village in hot summer and cold winter region of China. Build. Environ. 2015, 86, 151-165. [CrossRef]

52. Juan, X.; Ziliang, L.; Weijun, G.; Mengsheng, Y.; Menglong, S. The comparative study on the climate adaptability based on indoor physical environment of traditional dwelling in Qinba mountainous areas, China. Energy Build. 2019, 197, 140-155. [CrossRef]

53. Nguyen, A.-T.; Tran, Q.-B.; Tran, D.-Q.; Reiter, S. An investigation on climate responsive design strategies of vernacular housing in Vietnam. Build. Environ. 2011, 46, 2088-2106. [CrossRef]

54. Al-Obaidi, K.M.; Ismail, M.; Abdul Rahman, A.M. Design and performance of a novel innovative roofing system for tropical landed houses. Energy Convers. Manag. 2014, 85, 488-504. [CrossRef]

55. Su, B.; Aynsley, R. A Case Study of Roof Thermal Performance in Naturally Ventilated Houses in Hot-Humid Climates under Summer Conditions. Archit. Sci. Rev. 2006, 49, 399-407. [CrossRef]

56. Dabe, T.J.; Adane, V.S. The impact of building profiles on the performance of daylight and indoor temperatures in low-rise residential building for the hot and dry climatic zones. Build. Environ. 2018, 140, 173-183. [CrossRef]

57. Kim, G.; Yoo, J. Improvement of the Korean Design Criteria on Wall-To-Wall Junctions to Prevent Condensation in Apartment Houses. Sustainability 2019, 11, 3272.

58. Psomas, T.; Holzer, P.; Santamouris, M. A Naturally Ventilated Efficient Residential Building under the Impact of Climate Change. Int. J. Vent. 2014, 13, 169-178. [CrossRef]

59. Franco, L.C.; Mendes, J.C.; Costa, L.C.; Pira, R.R.; Peixoto, R.A. Design and thermal evaluation of a social housing model conceived with bioclimatic principles and recycled aggregates.(Report)(Author abstract). Sustain. Cities Soc. 2019, 51, 101725. [CrossRef]

60. Su, B. A Pilot Study on the Indoor Thermal Comfort of the "Wind-Rain" House. Int. J. Vent. 2011, 10, 79-87. [CrossRef]

61. Thateenaranon, P.; Amornkitbamrung, M.; Hirunlabh, J.; Khedari, J.; Waewsak, J. Full-scale field investigation of a bio-climatic house under Thailand tropical climate. Build. Environ. 2017, 126, 54-67. [CrossRef]

62. Karimpour, M.; Belusko, M.; Xing, K.; Boland, J.; Bruno, F. Impact of climate change on the design of energy efficient residential building envelopes. Energy Build. 2015, 87, 142-154. [CrossRef]

63. Khalil, A.-A.; Fikry, M.; Abdeaal, W. High technology or low technology for buildings envelopes in residential buildings in Egypt. Alex. Eng. J. 2018, 57, 3779-3792. [CrossRef]

64. Wong, S.L.; Wan, K.K.W.; Li, D.H.W.; Lam, J.C. Impact of climate change on residential building envelope cooling loads in subtropical climates. Energy Build. 2010, 42, 2098-2103. [CrossRef]

65. Makantasi, A.-M.; Mavrogianni, A. Adaptation of London's social housing to climate change through retrofit: A holistic evaluation approach. Adv. Build. Energy Res. 2016, 10, 99-124. [CrossRef]

66. Rockwood, D.; Da Silva, J.T.; Olsen, S.; Robertson, I.; Tran, T. Design and prototyping of a FRCC modular and climate responsive affordable housing system for underserved people in the pacific island nations. J. Build. Eng. 2015, 4, 268-282. [CrossRef]

67. Rodrigues, L.; Gillott, M. Climate resilience of a low-energy prototype house. Proc. Inst. Civ. Eng. Eng. Sustain. 2013, 166, 337-350. [CrossRef]

68. Santos, P.; Simões Da Silva, L.; Gervásio, H.; Gameiro Lopes, A. Parametric analysis of the thermal performance of light steel residential buildings in Csb climatic regions. J. Build. Phys. 2011, 35, 7-53. [CrossRef]

69. Gómez-Muñoz, V.M.; Porta-Gándara, M.A. Simplified architectural method for the solar control optimization of awnings and external walls in houses in hot and dry climates. Renew. Energy 2003, 28, 111-127. [CrossRef]

70. He, Q.; Ng, S.; Hossain, M.; Skitmore, M. Energy-Efficient Window Retrofit for High-Rise Residential Buildings in Different Climatic Zones of China. Sustainability 2019, 11, 6473. [CrossRef] 
71. Simá, E.; Chagolla-Aranda, M.; Huelsz, G.; Tovar, R.; Alvarez, G. Tree and neighboring buildings shading effects on the thermal performance of a house in a warm sub-humid climate. Build. Simul. 2015, 8, 711-723. [CrossRef]

72. Krzaczek, M.; Florczuk, J.; Tejchman, J. Field investigations of stack ventilation in a residential building with multiple chimneys and tilted window in cold climate. Energy Build. 2015, 103, 48-61. [CrossRef]

73. Kubota, T.; Chyee, D.T.H.; Ahmad, S. The effects of night ventilation technique on indoor thermal environment for residential buildings in hot-humid climate of Malaysia. Energy Build. 2009, 41, 829-839. [CrossRef]

74. Alam, M.; Sanjayan, J.; Zou, P.X.W.; Ramakrishnan, S.; Wilson, J. Evaluating the passive and free cooling application methods of phase change materials in residential buildings: A comparative study. Energy Build. 2017, 148, 238-256. [CrossRef]

75. Baneshi, M.; Gonome, H.; Maruyama, S. Cool black roof impacts into the cooling and heating load demand of a residential building in various climates. Sol. Energy Mater. Sol. Cells 2016, 152, 21-33. [CrossRef]

76. Baneshi, M.; Maruyama, S. The impacts of applying typical and aesthetically-thermally optimized TiO2 pigmented coatings on cooling and heating load demands of a typical residential building in various climates of Iran. Energy Build. 2016, 113, 99-111. [CrossRef]

77. Cao, B.; Zhu, Y.; Li, M.; Ouyang, Q. Individual and district heating: A comparison of residential heating modes with an analysis of adaptive thermal comfort. Energy Build. 2014, 78, 17-24. [CrossRef]

78. Viegas, G.M.; Jodra, J.I.; San Juan, G.A.; Díscoli, C.A. Heat storage wall made of concrete and encapsulated water applied to mass construction social housing in temperate climates. Energy Build. 2018, 159, 346-356. [CrossRef]

79. Mahmoud, A.; Asif, M.; Hassanain, M.; Babsail, M.; Sanni-Anibire, M. Energy and Economic Evaluation of Green Roofs for Residential Buildings in Hot-Humid Climates. Buildings 2017, 7, 30. [CrossRef]

80. Sfakianaki, A.; Pagalou, E.; Pavlou, K.; Santamouris, M.; Assimakopoulos, M.N. Theoretical and experimental analysis of the thermal behaviour of a green roof system installed in two residential buildings in Athens, Greece. Int. J. Energy Res. 2009, 33, 1059-1069. [CrossRef]

81. Gaspari, J.; Naboni, E.; Ponzio, C.; Ricci, A. A study on the impact of climate adaptive building shells on indoor comfort. J. Facade Des. Eng. 2019, 7, 27-39.

82. Bakirci, K.; Yuksel, B. Experimental thermal performance of a solar source heat-pump system for residential heating in cold climate region. Appl. Therm. Eng. 2011, 31, 1508-1518. [CrossRef]

83. Lindelöf, D.; Afshari, H.; Alisafaee, M.; Biswas, J.; Caban, M.; Mocellin, X.; Viaene, J. Field tests of an adaptive, model-predictive heating controller for residential buildings. Energy Build. 2015, 99, 292-302. [CrossRef]

84. Macias, M.; Gaona, J.; Luxan, J.; Gomez, G. Low cost passive cooling system for social housing in dry hot climate. Energy Build. 2009, 41, 915-921. [CrossRef]

85. Wang, X.; Khoo, Y.B.; Wang, C.H. Risk assessment and decision-making for residential housing adapting to increasing storm-tide inundation due to sea-level rise in South East Queensland. Aust. Civ. Eng. Environ. Syst. 2013, 31, 125-139. [CrossRef]

86. Wilson, C.; Wilson, C.; Hargreaves, T.; Hargreaves, T.; Hauxwell-Baldwin, R.; Hauxwell-Baldwin, R. Smart homes and their users: A systematic analysis and key challenges. Pers. Ubiquitous Comput. 2015, 19, 463-476. [CrossRef]

87. Dodoo, A.; Ayarkwa, J. Effects of climate change for thermal comfort and energy performance of residential buildings in a Sub-Saharan African climate. Buildings 2019, 9, 215. [CrossRef]

88. Ali, A.A.M. Using simulation for studying the influence of horizontal shading device protrusion on the thermal performance of spaces in residential buildings. Alex. Eng. J. 2013, 52, 787-796. [CrossRef]

89. Yu, C.; Xu, Y.; Song, Y. The Effects of Courtyards on the Thermal Performance of a Vernacular House in a Hot-Summer and Cold-Winter Climate. Energies 2019, 12, 1042.

90. Arman, H. Assessment of solar shading strategies in low-income tropical housing: The case of Uganda. Proc. Inst. Civ. Eng. 2019, 172, 293-301.

91. Porritt, S.; Shao, L.; Cropper, P.; Goodier, C. Adapting dwellings for heat waves. Sustain. Cities Soc. 2011, 1, 81-90. [CrossRef]

92. Sehizadeh, A.; Ge, H. Impact of future climates on the durability of typical residential wall assemblies retrofitted to the PassiveHaus for the Eastern Canada region. Build. Environ. 2016, 97, 111-125. [CrossRef]

93. Nik, V.M.; Mata, E.; Sasic Kalagasidis, A.; Scartezzini, J.-L. Effective and robust energy retrofitting measures for future climatic conditions-Reduced heating demand of Swedish households. Energy Build. 2016, 121, 176-187. [CrossRef]

94. Porritt, S.; Cropper, P.C.; Shao, L.; Goodier, C.I. Heat wave adaptations for UK dwellings and development of a retrofit toolkit. Int. J. Disaster Resil. Built Environ. 2013, 4, 269-286. [CrossRef]

95. Grussa, Z.D.; Andrews, D.; Lowry, G.; Newton, E.J.; Yiakoumetti, K.; Chalk, A.; Bush, D. A London residential retrofit case study: Evaluating passive mitigation methods of reducing risk to overheating through the use of solar shading combined with night-time ventilation. Build. Serv. Eng. Res. Technol. 2019, 40, 389-408. [CrossRef]

96. Conde, C.; Lonsdale, K.; Nyong, A.; Aguilar, Y. Engaging Stakeholders in the Adaptation Process; Cambridge University Press: Cambridge, UK, 2004.

97. Czischke Ljubetic, D.K. Collaborative housing and housing providers: Towards an analytical framework of multi-stakeholder collaboration in housing co-production. Int. J. Hous. Policy 2017, 18, 55-81. [CrossRef]

98. United Nations. Sustainable Development Goals Knowledge Platform. Available online: https://sustainabledevelopment.un. org/post2015/transformingourworld (accessed on 10 December 2020). 